\title{
PEG-8000 Alters Morphology and Nutrient Concentration of Hydroponic Impatiens
}

Stephanie Burnett ${ }^{1}$

Department of Plant, Soil, and Environmental Sciences, University of Maine, 5722 Deering Hall, Orono, ME 04469

Marc van Iersel and Paul Thomas

Department of Horticulture, University of Georgia, 1111 Miller Hall Plant Sciences Building, Athens, GA 30602

Additional index words. Impatiens walleriana, polyethylene glycol, drought, growth retardant

\begin{abstract}
Osmotic compounds, such as polyethylene glycol 8000 (PEG-8000), reduce plant elongation by imposing controlled drought. However, the effects of PEG-8000 on nutrient uptake are unknown. Impatiens 'Dazzler Pink' (Impatiens walleriana Hook. F.) were grown hydroponically in modified Hoagland solutions containing $0,10,17.5,25,32.5,40,47.5,55$, or $62.5 \mathrm{~g} \cdot \mathrm{L}^{-1} \mathrm{PEG}-8000$. Impatiens were up to $68 \%$ shorter than control plants when grown with PEG-8000 in the nutrient solution. Plants treated with PEG-8000 rates above $25 \mathrm{~g} \cdot \mathrm{L}^{-1}$ were either damaged or similar in size to seedlings treated with $25 \mathrm{~g} \cdot \mathrm{L}^{-1}$ of PEG-8000. Impatiens leaf water potentials $\left(\Psi_{w}\right)$ were positively correlated with plant height. PEG-8000 reduced the electrical conductivity of Hoagland solutions as much as $\mathbf{4 0 \%}$ compared to nontreated Hoagland solutions, suggesting that PEG-8000 may bind some of the nutrient ions in solution. Foliar tissue of PEG-treated impatiens contained significantly less nitrogen, calcium, zinc, and copper, but significantly more phosphorus and nickel than tissue from nontreated impatiens. However, no nutrient deficiency symptoms were induced.
\end{abstract}

Impatiens (Impatiens walleriana Hook. F.) are popular summer annuals in the United States and are grown for their diverse colorful flowers and growth forms. Impatiens are useful in the landscape since they flower in shade. Unfortunately, under commercial greenhouse conditions (high temperatures and possibly high plant density), impatiens elongate rapidly, becoming leggy, more difficult to water, more expensive to ship, and less attractive than shorter plants. Greenhouse growers may reduce elongation of bedding plants with chemical plant growth retardants (Bailey and Whipker, 1998). However, if greenhouse workers over-apply plant growth retardants, plants will be stunted, and the sale date of plants may be delayed or plants may not be saleable. Nonchemical height control methods include brushing the shoots (Latimer, 1991; Mitchell, 1996), withholding nutrients (Huang et al., 2002), or applying negative DIF (day temperature - night temperature) (Erwin et al., 1989). Unfortunately, nonchemical growth control tends to be expensive or, if used improperly, may damage plants (Amsen and Nielsen, 1991; Huang et al., 2002; Latimer, 1994).

Another height control option for green-

Received for publication 16 Feb. 2005. Accepted for publication 8 May 2005. Based on part of a dissertation in partial fulfillment of the requirements for a $\mathrm{PhD}$ degree at the University of Georgia. We thank Carrie Radcliffe and Matt Hawkins for technical assistance and Bodie Pennisi, Hugh Earl, Peter Hartel, and Hazel Wetzstein for their helpful comments on an early draft of this manuscript.

${ }^{1}$ To whom reprint requests should be addressed; e-mail seburnett@mindspring.com. house growers is drought-stressing plants to slow growth. Plants grown with minimal water grow more slowly than those with adequate water because the rate of cell enlargement is partially controlled by turgor potential $\left(\Psi_{p}\right)$. In addition to other factors, cell $\Psi_{\mathrm{w}}$ determines $\Psi_{\mathrm{p}}$ (van Volkenburgh, 1999). Since the cell $\Psi_{w}$ is influenced by soil $\Psi_{w}$, decreasing soil $\Psi_{w}$ may decrease cell enlargement and plant growth. For this reason, horticultural plants are often allowed to wilt or are grown in substrates close to the point where plants would wilt to reduce growth (Latimer and Severson, 1997; Liptay et al., 1998). Water requirements for most horticultural crops are unknown; so drought stressing plants to reduce growth often requires guesswork for growers. This can be deleterious for plants because, if water is restricted too much, stomata will close, and photosynthesis will decrease (Mohr and Schopfer, 1995). On a morphological level, severe symptoms of drought stress may include leaf abscission, scorching, or in extreme cases, plant death.

Adding osmotic compounds, such as polyethylene glycol (PEG) to a substrate imposes controlled drought stress. Marigold (Tagetes patula L.) and salvia (Salvia splendens F. Sellow. ex Roem \& Shult.) seedlings treated with PEG growing medium drenches are shorter than nontreated plants (Burnett et al., 2004b). Low rates of PEG ( 15 to $30 \mathrm{~g} \cdot \mathrm{L}^{-1}$ ) do not visibly damage seedlings (Burnett et al., 2004b). PEG-8000 may be applied to seedlings before or shortly after emergence, and it reduces hypocotyl elongation (Burnett, 2004; Burnett et al., 2004b). Osmotic compounds fill a niche for early height control of ornamental seedlings, since chemical growth retardants are usually applied after the first true leaves emerge (Uniroyal Chemical, 2000).

PEG reduces the matric potential of substrates by forming hydrogen bonds with water (Kjellander and Florin, 1981; Steuter, 1981). It has not been reported that PEG- 8000 forms bonds with nutrient ions or impacts nutrient uptake. However, electrical conductivity, which estimates the nutrient content of the substrate solution, decreases with increasing PEG concentration (Burnett, 2004), suggesting that PEG may affect nutrient availability. Before PEG- 8000 is recommended to growers, it is important to understand whether typical fertilization practices must be altered. Therefore, the main purpose of this experiment was to determine whether plant nutrient concentration is affected by PEG-8000. We also determined how PEG-8000 affects impatiens morphology. This experiment was conducted in hydroponic culture, rather than in a soilless growing medium to have more control over the nutrient composition of the substrate.

\section{Materials and Methods}

Impatiens 'Dazzler Pink' (Impatiens walleriana Hook. F.; Ball Seed Co., West Chicago, Ill.) seeds were planted in germination trays (without individual cells for each plant) containing vermiculite on 2 Sept. 2003. Seeds were germinated on a mist bench irrigated $5 \mathrm{~s}$ every 5 min from 8:00 AM until 5:00 PM and grown in a glass greenhouse (temperature minimum $=17.6{ }^{\circ} \mathrm{C} \pm 2.3{ }^{\circ} \mathrm{C}$; maximum $=29.7{ }^{\circ} \mathrm{C} \pm$ $4.4^{\circ} \mathrm{C}$; Maximum daily $P P F$ levels $=800 \pm$ $\left.210 \mu \mathrm{mol} \cdot \mathrm{m}^{-2} \cdot \mathrm{s}^{-1}\right)$. Plants were transplanted into plastic tubs (4.5 L capacity) containing modified Hoagland solution (Hoagland and Arnon, 1950) $45 \mathrm{~d}$ after seeds were planted. At this point, seedling roots were at least 5 $\mathrm{cm}$ long. The seedlings were supported within trays by polyester batting. Subdue Maxx fungicide (Mefonoxam, Syngenta Chemical, Greensboro, N.C.) was added biweekly at a rate of $0.125 \mathrm{~mL} \cdot \mathrm{L}^{-1}$ of Hoagland solution to all plastic tubs to prevent Pythium and Phytophthora infection.

PEG-8000 was added to Hoagland solutions after plants were acclimated to hydroponic conditions for $13 \mathrm{~d}$. PEG- 8000 rates were 0 , $10,17.5,25,32.5,40,47.5,55$, or $62.5 \mathrm{~g} \cdot \mathrm{L}^{-1}$. PEG was added at dusk and in a step-wise manner over a period of $8 \mathrm{~d}$. On the first evening, the lowest PEG concentration was added to all containers except controls. On the following days, $7.5 \mathrm{~g} \cdot \mathrm{L}^{-1}$ of PEG was added to containers each day as necessary to attain the appropriate PEG concentrations. After $8 \mathrm{~d}$, PEG had been added to all containers at the appropriate concentrations. PEG was added in this manner to allow plants to slowly acclimate to the presence of PEG. Additional Hoagland solution, without PEG, was added to the tubs as needed to maintain a constant volume of nutrient solution.

Hoagland solutions were changed 58 and $78 \mathrm{~d}$ after seeding impatiens to reduce the risk of fungal contamination. The new solutions contained appropriate amounts of PEG-8000 
for each treatment. Electrical conductivity and $\mathrm{pH}$ were measured twice weekly with a meter with interchangeable sensors for measuring electrical conductivity and $\mathrm{pH}$ (M90; Corning Inc., Corning, N.Y.). Liquid flowable lime (Limestone F, Cleary Chemical, Dayton, N.J.) or dilute sulfuric acid were added to the solutions to maintain a $\mathrm{pH}$ within the range of 5.5 to 7.5 .

Plant height and width were recorded $98 \mathrm{~d}$

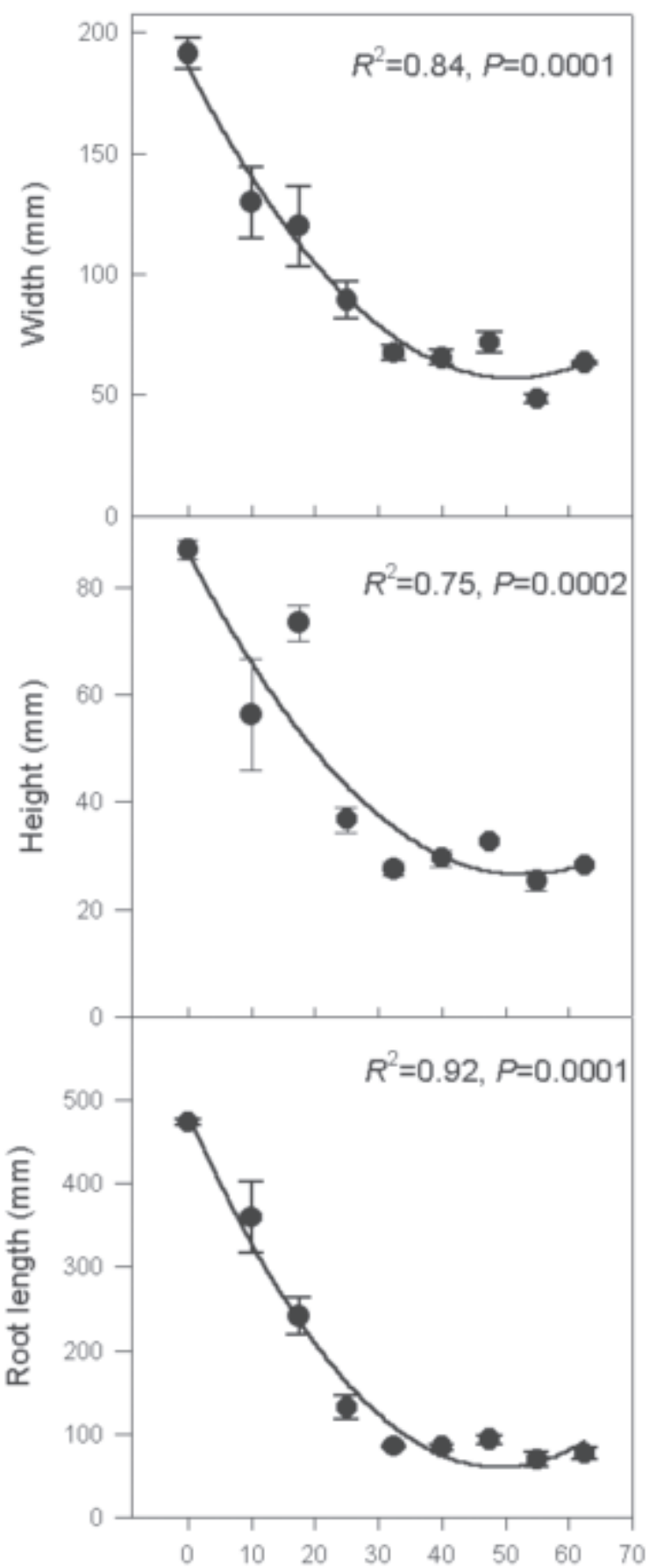

PEG in Hoagland solution $\left(\mathrm{g} \mathrm{L}^{-1}\right)$

Fig. 1. Effects of PEG-8000 concentrations in Hoagland solution on height, width, and root length of impatiens at harvest (98 d after seeding). Data points are the mean of two blocks with standard errors; standard errors not shown are within the limit of the symbols. Regression lines indicate significant linear or quadratic trends. dried in a forced-air oven at $80^{\circ} \mathrm{C}$ for at least 3 $\mathrm{d}$, and then tissue dry weights were recorded. Compactness was calculated from these data [compactness $=$ leaf area/height $(\mathrm{m})$ or shoot dry weight/height $\left.\left(\mathrm{g} \cdot \mathrm{m}^{-1}\right)\right]$.

Midday leaf $\Psi_{\mathrm{w}}\left[\Psi_{\mathrm{w}}=\Psi_{\mathrm{p}}+\right.$ solute potential $\left.\left(\Psi_{\mathrm{s}}\right)\right]$ of the uppermost fully expanded leaf was measured using leaf-cutter thermocouple Leaf area was measured with a leaf area meter and shoots (stems and leaves), were
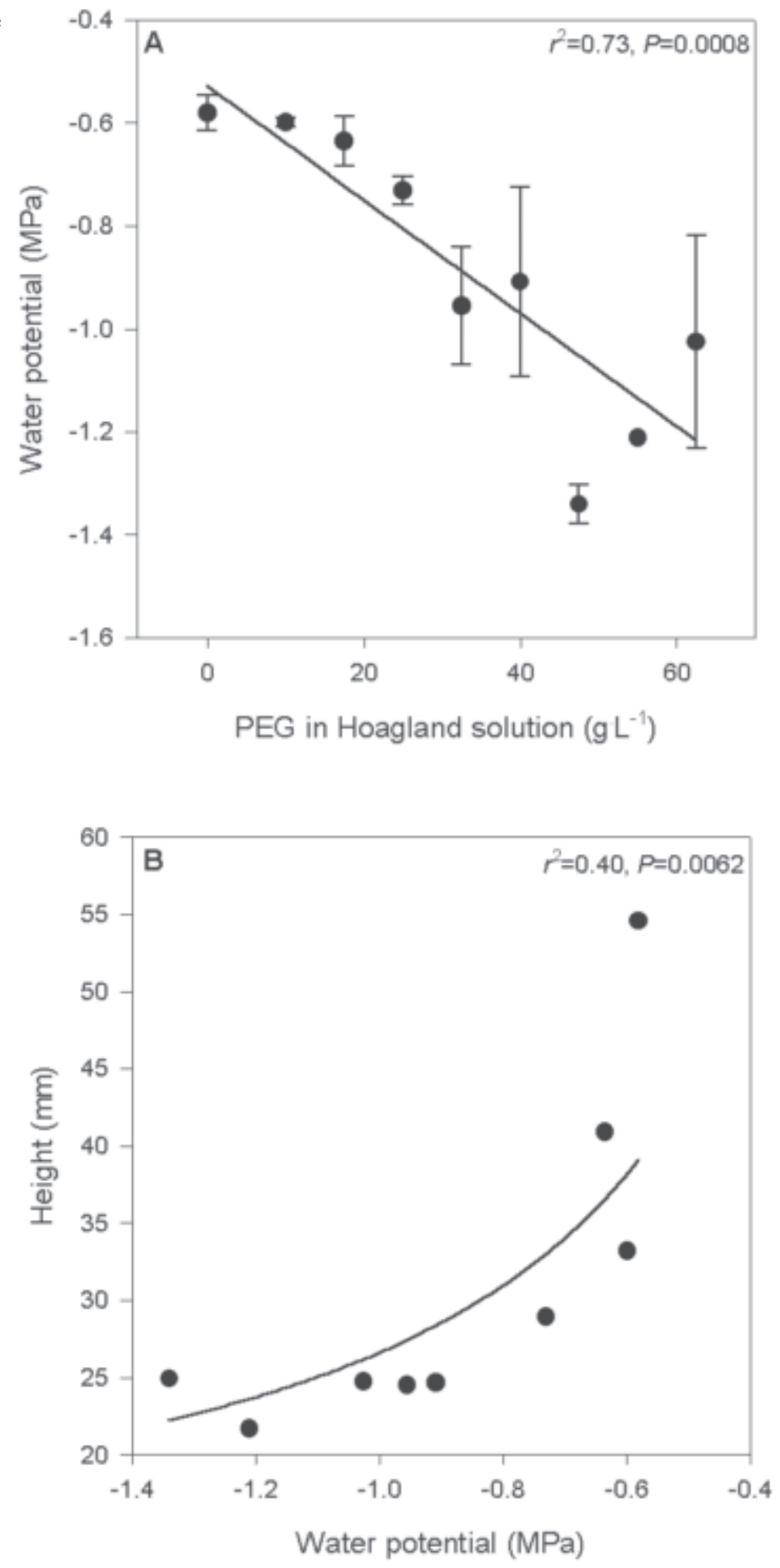

Fig. 2. (A) Effects of PEG-8000 in Hoagland solution on impatiens leaf water potential. (B) Effects of leaf $\Psi_{w}$ on impatiens height. Data points are the mean of two blocks for both graphs. Standard deviations are shown for $\mathbf{A}$; standard deviations not shown are due to missing values. The regression line indicates a significant linear or inverse polynomial trend. 
psychrometers $84 \mathrm{~d}$ after seeding (model 842VC; J.R.D. Merrill Specialty Equipment, Logan, Utah). Leaf samples enclosed in the psychrometer chambers were equilibrated in a water bath at $25^{\circ} \mathrm{C}$ for $4 \mathrm{~h}$ before measurement. $\Psi_{\mathrm{w}}$ of the intact leaf samples was measured using a microvoltmeter (J.R.D. Specialty Equipment). At the termination of the experiment, foliar tissue of impatiens was analyzed at a local soil, plant, and water analysis lab (University of Georgia Soil, Plant, and Water Analysis Laboratory, Athens, Ga.) for mineral nutrient concentration.

Treatments were arranged in a randomized complete block design with two blocks. A single experimental unit consisted of a plastic container with six plants (subsamples). Data collected for the subsamples were averaged within each experimental unit before statistical analysis. Both blocks were combined for foliar tissue analysis because plants grown in the treatments with the four highest PEG concentrations were too small to be analyzed for each block individually. Data were analyzed by testing for significant linear and quadratic effects of the PEG concentrations on the various parameters using general linear models in Statistical Analysis System (SAS, Cary, N.C.). Impatiens leaf $\Psi_{\mathrm{w}}$ was compared to height $84 \mathrm{~d}$ after seeding also using general linear models. Foliar nutrient concentrations were analyzed using regression analysis (SAS, Cary, N.C.).

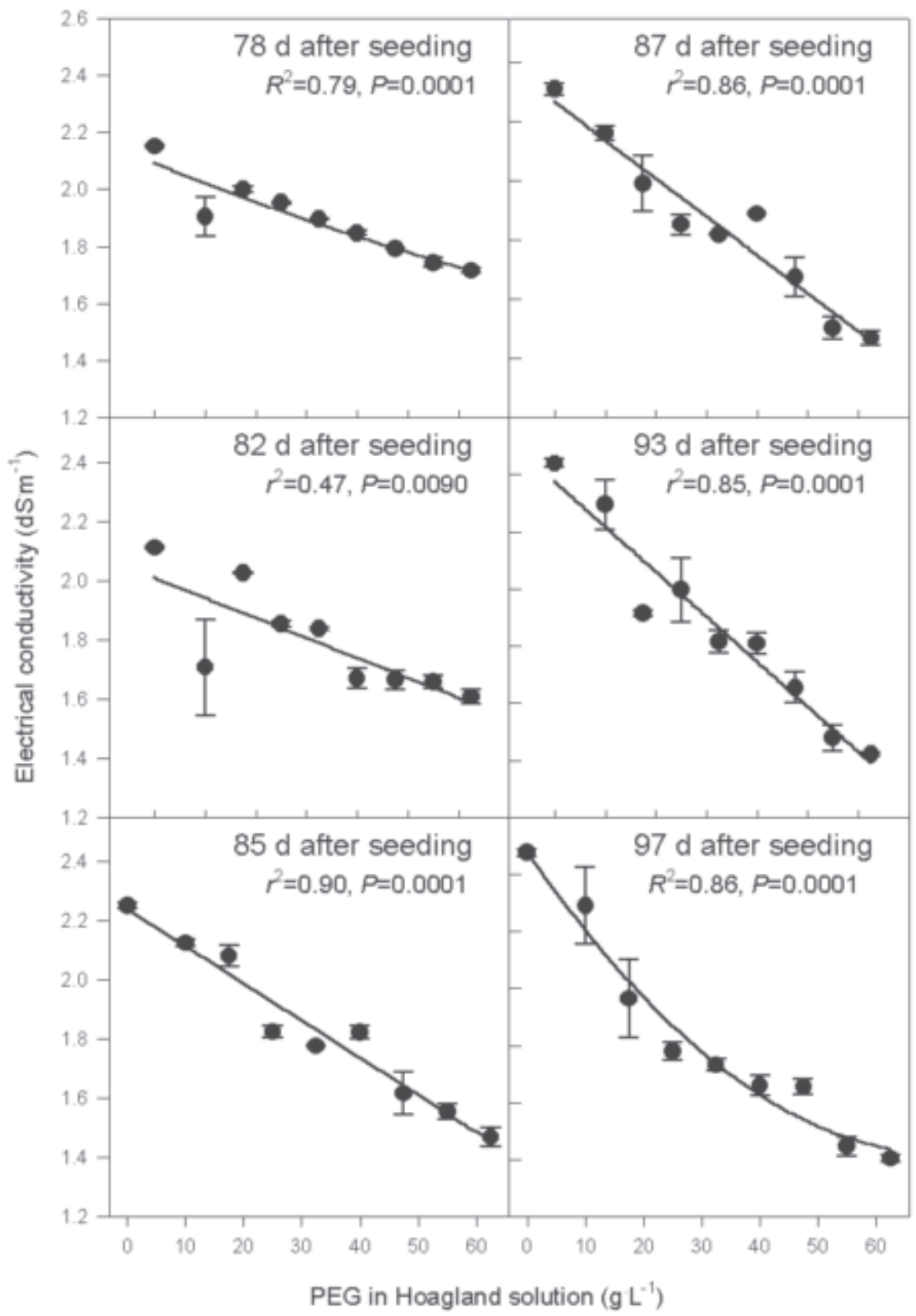

Fig. 3. Effects of PEG- 8000 concentrations on Hoagland solution electrical conductivity. Data are presented for impatiens' Hoagland solutions 78, 82, 85, 87, 93, and $97 \mathrm{~d}$ after seeding. These data are representative of the trends for the entire experiment. Data points are the mean of two blocks with standard error; standard errors not shown are within the limit of the symbols. Regression lines indicate significant linear or quadratic trends.

\section{Results and Discussion}

Morphology. Impatiens were shorter and narrower when grown in solutions containing increasing PEG-8000 concentrations (Fig. 1). They were up to $68 \%$ shorter and $67 \%$ less wide at harvest than nontreated impatiens. Similar results were obtained when marigolds and salvias were treated with PEG-8000 incorporated into or applied as a drench in the growing medium (Burnett, 2004; Burnett et al., 2004a, 2004b). Root length was up to $84 \%$ less at harvest when seedlings were treated with increasing concentrations of PEG-8000 (Fig. 1). Impatiens roots harvested from plants grown in the two highest concentrations appeared black and did not grow much, if at all, after the addition of PEG to Hoagland solutions. In this experiment, concentrations of PEG-8000 $>25$ $\mathrm{g} \cdot \mathrm{L}^{-1}$ provided no additional height reduction, since all impatiens treated with $>32.5 \mathrm{~g} \cdot \mathrm{L}^{-1}$ of PEG-8000 had similar heights at the end of the experiment. Since root lengths decreased with the addition of more PEG, using $<32$ $\mathrm{g} \cdot \mathrm{L}^{-1}$ would be best.

At harvest, PEG-treated impatiens were less compact than nontreated controls when compactness was measured as either the ratio of leaf area or shoot dry weight to height (Burnett, 2004). Compactness of impatiens treated with PEG-8000 decreased quadratically up to $76 \%$ (leaf area/height) or $72 \%$ (dry weight/height) (leaf area/height $=0.38-7.83$ $\times 10^{-3} \mathrm{x}+4.97 \mathrm{H} 10^{-5} \mathrm{x}^{2}, R^{2}=0.84, P=0.0001$; dry weight $/$ height $=0.094-0.610 \mathrm{x}-7.00 \mathrm{x}^{2}$, $R^{2}=0.77, P=0.0001 ; \mathrm{x}=$ PEG-concentration in $\left.\mathrm{g} \cdot \mathrm{L}^{-1}\right)$. Although PEG-treated plants were smaller, nontreated plants were more compact (i.e., more leaf area or dry weight per unit plant height). Compactness traditionally has not been measured in growth retardant studies; however, drought-stressed and PEGtreated marigolds were also smaller, but less compact, than control plants (Burnett, 2004; van Iersel and Nemali, 2004). It may be more important to decrease height than to increase compactness, since shorter plants are cheaper to ship and generally of higher quality than tall, leggy plants. Impatiens shoot dry weight and leaf area significantly decreased up to $92 \%$ at harvest (Burnett, 2004; leaf area $=311-11.59$ $\mathrm{x}+0.115 \mathrm{x}^{2}, R^{2}=0.90, P=0.0001 ; \mathrm{x}=$ PEGconcentration in $\mathrm{g} \cdot \mathrm{L}^{-1}$ ).

Leaf $\Psi_{w}$ decreased with increasing PEG8000 concentration in Hoagland solutions (Fig. $2 \mathrm{~A}$ ), and leaf $\Psi_{w}$ was positively correlated with height $84 \mathrm{~d}$ after seeding (Fig. 2B). The correlation between height and $\Psi_{w}$ was not a strong fit to an inverse polynomial model.

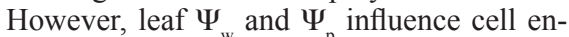
largement throughout the growth period. For this reason, a single measurement may not be closely correlated to height. Turgor potential is one component of $\Psi_{w}$, and it is the driving force behind cell enlargement (Lockhart, 1965). In further experiments examining the use of PEG-8000 to control bedding plant stem elongation, we found that leaf $\Psi_{w}, \Psi$, and $\Psi_{\mathrm{s}}$ decreased with increasing PEG- 8000 concentration (Burnett, 2004). Thus, it appears that PEG-8000 reduced elongation of impatiens 

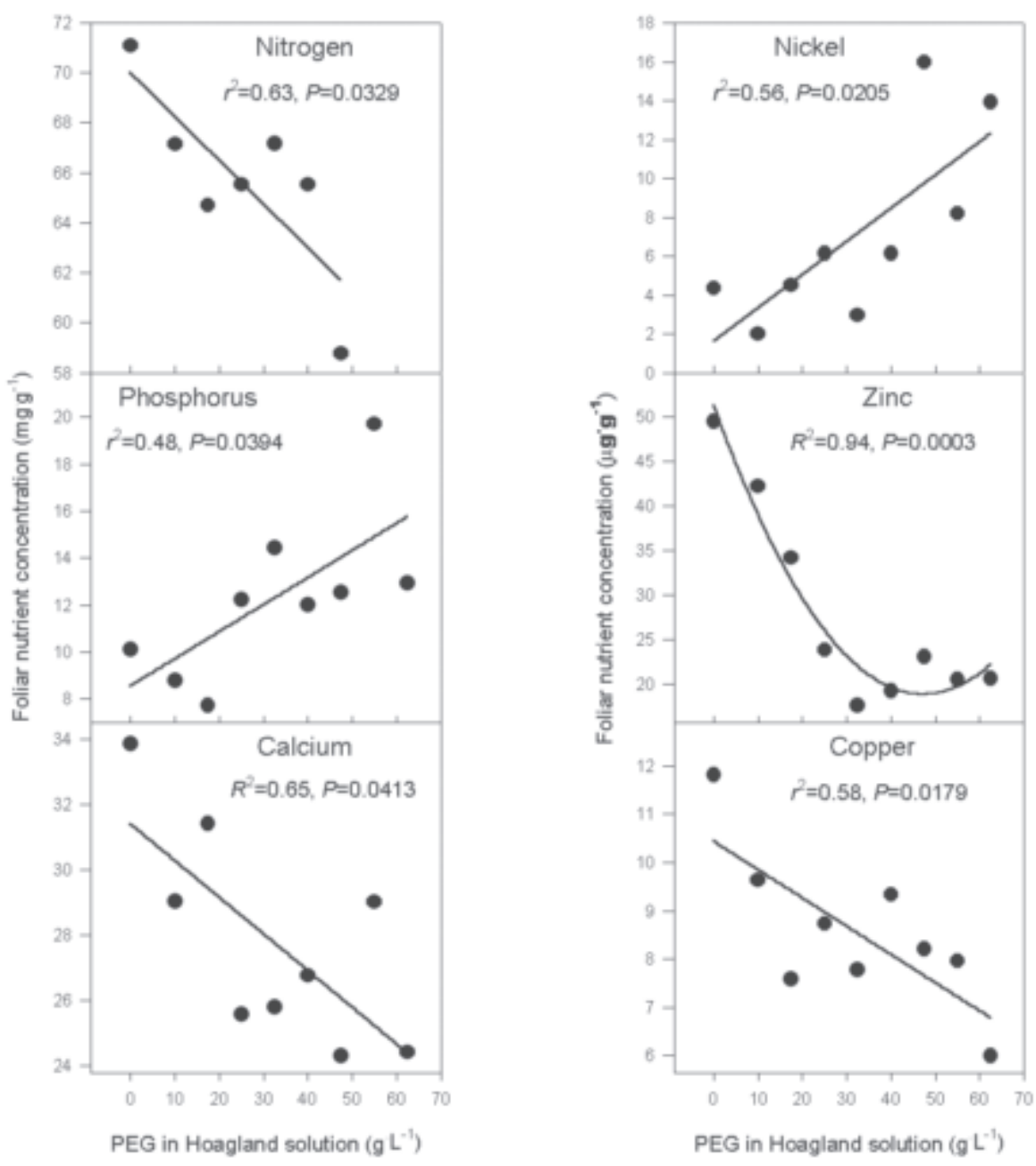

Fig. 4. Effects of PEG-8000 concentrations in Hoagland solution on impatiens' foliar nutrient concentrations. Data are only presented for those macro- and micronutrients that were significantly affected by PEG-8000 concentration. Regression lines indicate significant linear or quadratic trends.

at least in part by reducing leaf $\Psi_{w}$

Electrical conductivity and nutrient analysis. Electrical conductivities of Hoagland solutions decreased significantly with the addition of PEG-8000 (Fig. 3). This has not been reported previously. Conductivity of solutions increases with increasing mineral nutrient concentration (Whipker and Cavins, 2000). Since PEG-8000 is a polar compound, it likely forms bonds with ionic minerals in addition to water in Hoagland solutions. Undoubtably, the relationship among nutrient uptake, PEG8000 , mineral nutrients, and water in Hoagland solution is more complex than a simple ionic bonding relationship. For example, if mineral nutrients form chemical bonds with PEG-8000, are they unavailable for plant uptake?

PEG-4000 decreased nutrient content in hydroponically grown corn (Izzo et al., 1989). However, nutrient quantities were expressed per plant, not per unit dry weight. Since we observed that PEG decreased growth, nutrient contents would naturally be lower in smaller plants. Unfortunately, Izzo et al. (1989) did not report height and dry weight, so it is unclear if nutrient content was lower because of lower nutrient concentrations in the tissue, or a decrease in plant size. Foliar tissue analysis of the impatiens revealed that nitrogen, calcium, zinc, and copper concentrations decreased with increasing PEG-8000 concentrations, while nickel and phosphorus increased with increasing concentrations of PEG-8000 in the Hoagland solutions (Fig. 4).

Zinc and copper were present at concentrations below the recommended range for impatiens (recommended for zinc, 57 to 67 $\mu \mathrm{g} \cdot \mathrm{g}^{-1}$; for copper, 20 to $37 \mu \mathrm{g} \cdot \mathrm{g}^{-1}$; Mills and Jones, 1996) in all treatments. According to Marschner (1995), symptoms of copper and zinc deficiencies include reduced growth; however, levels of these nutrients were deficient in control plants as well, and thus not the likely cause of the observed growth reductions. Nitrogen and calcium levels were also significantly lower with increasing PEG concentrations. However, since levels never dropped below recommended rates (Mills and Jones, 1996), the observed reductions in nitrogen and calcium probably did not affect plant growth. So, the observed height differences cannot be explained from PEG-induced nutrient deficiencies, especially since plants did not show visual deficiency symptoms typical for zinc or copper (Mills and Jones, 1996). All impatiens, including controls, had slight interveinal chlorosis early in the experiment. These symptoms were not due to the presence of PEG-8000 since they were present in all treatments.

Phosphorus concentrations increased with PEG, which may be related to the low zinc concentrations. Zinc deficiencies are associated with increased phosphorus uptake and translocation to shoot tissues (Marschner, 1995). Nickel concentrations also increased with increasing PEG rates, but no research has determined the effects of nickel on impatiens growth; in fact, no recommended levels for nickel concentrations in impatiens are available in the literature. However, nickel levels in two of the higher PEG treatments are above general recommended levels for Ni-sensitive species (Marschner, 1995). The PEG-8000 in this experiment contains trace amounts of nickel $(\leq 0.0005 \%)$, which may explain the increase in nickel with increasing PEG concentrations. Also, the observed increase in both nickel and phosphorus concentrations in the impatiens may simply be an artifact of the reduced growth. The increased growth at low PEG concentrations may have resulted in a dilution of these nutrients.

Although it is possible that reduced tissue concentrations of zinc, copper, and calcium could be caused by binding of these ions to the PEG-8000, observed decreases in electrical conductivity with increasing PEG concentration (Fig. 3) are not likely to be explained solely by possible binding of these nutrients to PEG-8000, since these ions only represent a small component of the total nutrient content in Hoagland solution. This decrease in electrical conductivity was observed even in newly prepared PEG-8000 solutions, so it is probably related to nutrient absorption to polar sites on PEG. It is possible that nutrients are bound by PEG- 8000 in solution, but are still available for plant uptake, much like cations that are temporarily adsorbed at exchange sites on soil colloids.

Over time, electrical conductivity increased in the control treatment, stayed the same in the lower level PEG treatments $(10,17.5,25$, and $\left.40 \mathrm{~g} \cdot \mathrm{L}^{-1}\right)$, and decreased in high level PEG treatments $\left(32.5,47.5,55\right.$, and $\left.62.5 \mathrm{~g} \cdot \mathrm{L}^{-1}\right)$ (Burnett, 2004). This likely is related to differences in the ratio between water and nutrient uptake among treatments. Stomata will close when water availability decreases (Taiz and Zeiger, 1998) (i.e., at high PEG concentrations), thus reducing transpiration and water uptake by the plants. Since nutrient uptake is not directly related to water uptake (i.e., most nutrients are taken up actively), PEG may affect transpiration more than nutrient uptake. A decrease in water uptake without a concomitant decrease in nutrient uptake will result in a decrease in the nutrient concentration of the solution, and thus a decrease in electrical conductivity.

\section{Conclusions}

PEG- 8000 concentrations of $25 \mathrm{~g} \cdot \mathrm{L}^{-1}$ reduce growth of impatiens in nutrient culture without damaging roots or reducing plant quality. Rates $>47.5 \mathrm{~g} \cdot \mathrm{L}^{-1} \mathrm{PEG}-8000$ resulted in plants 
with small, black root systems and little or no new shoot growth. Elongation of impatiens was reduced by PEG-8000 at least in part because of lower leaf $\Psi$. PEG-8000 reduced electrical conductivity of Hoagland solutions by up to $1 \mathrm{dS} \cdot \mathrm{m}^{-1}$. PEG-treated impatiens had less zinc, copper, nitrogen, and calcium and more phosphorus and nickel than nontreated controls. Zinc and copper were deficient in all impatiens, including nontreated controls. No other nutrients were deficient. Since PEG did not induce any visible nutritional deficiency symptoms, it appears that PEG reduces height mainly by reducing substrate $\Psi_{w}$. Further work should be conducted to determine whether PEG-8000 changes plant nutrient requirements in soilless growing media.

\section{Literature Cited}

Amsen, M.G. and O.F. Nielsen. 1991. Negative DIF: Mean room temperature control and its effect on environment and energy consumption. Tidsskrift for Planteavl 95:433-439.

Bailey, D. and B. Whipker. 1998. Height control of commercial greenhouse flowers. N.C. Coop. Ext. Serv. Hort. Info. Lflt. 528.

Burnett, S. 2004. Effects of polyethylene glycol on the morphology of ornamental seedlings. PhD diss. Univ. Ga., Athens.

Burnett, S.E., S.V. Pennisi, P.A. Thomas, and M.W. van Iersel. 2004a. Controlled drought affects morphology and anatomy of Salvia splendens. J. Amer. Soc. Hort. Sci. (in press).

Burnett, S.E., P.A. Thomas, and M.W. van Iersel. 2004b. Post-germination drenches with PEG8000 reduce growth of salvia and marigold. HortScience (in press).

Erwin, J.E., R.D. Heins, and M.G. Karlsson. 1989. Thermomorphogenesis in Lilium longiflorum. Amer. J. Bot. 76:47-52.

Hoagland, D.R. and D.I. Arnon. 1950. The waterculture method for growing plants without soil. Calif. Agr. Expt. Sta. Circ. 347 (revised 1950).

Huang, J.S., P.V. Nelson, D.A. Bailey, W.C. Fonteno, and N.C. Mingis. 2002. Assessment of the need for nitrogen, phosphorus, potassium, and sulfur preplant nutrients for plug seedling growth. HortScience 37:529-533.

Izzo, R., F. Navari-Izzo, and M.F. Quartacci. 1989. Growth and mineral content of roots and shoots of maize seedlings in response to increasing water deficits induced by PEG solutions. J. Plant Nutr. 12:1175-1193.

Kjellander, R. and E. Florin. 1981. Water structure and changes in thermal stability of the system poly (ethylene oxide)-water. J. Chem. Soc., Faraday Trans. I. 77:2053-2077.

Latimer, J.G. 1991. Mechanical conditioning for control of growth and quality of vegetable transplants. HortScience 26:1456-1461.

Latimer, J.G. 1994. Pepper transplants are excessively damaged by brushing. HortScience 29:1002-1003.

Latimer, J.G. and R.F. Severson. 1997. Effect of mechanical and moisture-stress conditioning on growth and cuticle composition of broccoli transplants. J. Amer. Soc. Hort. Sci. 122:788-791.

Liptay, A., P. Sikkema, and W. Fonteno. 1998. Transplant growth control through water deficit stress-A review. HortTechnology 8:540-543.

Lockhart, J.A. 1965. An analysis of irreversible plant cell elongation. J. Theoretical Biol. 8:264-275.

Marschner, H. 1995. Mineral nutrition of higher plants. 2nd ed. Academic Press, London.

Mills, H.A. and J.B. Jones, Jr. 1996. Plant analysis handbook II: A practical sampling, preparation, analysis, and interpretation guide. MicroMacro Publishing, Athens, Ga.

Mitchell, C.A. 1996. Recent advances in plant responses to mechanical stress: Theory and application. HortScience 31:31-35.

Mohr, H. and P. Schopfer. 1995. Plant physiology. Springer-Verlag, Berlin, Germany.

Steuter, A.A., A. Mozafar, and J.R. Goodin. 1981 Water potential of aqueous polyethylene glycol. Plant Physiol. 67:64-67.

Taiz, L. and E. Zeiger. 1998. Plant physiology. 2nded. Sinauer Associates, Inc., Sunderland, Mass.

Uniroyal Chemical. 2000. Bonzi: Ornamental growth regulator (product label). Uniroyal Chemical.

van Iersel, M.W. and K.S. Nemali. 2004. Drought stress can produce small, but not compact marigolds. HortScience 39:1298-1301.

van Volkenburgh, E. 1999. Leaf expansion-An integrating plant behavior. Plant Cell Environ. 22:1463-1473.

Whipker, B.E. and T.J. Cavins. 2000. Electrical conductivity (EC): Units and conversions. N.C. Coop. Ext. Serv. Florex.002. 